\title{
LA PERSPECTIVA CRANE. LA CRISIS DE IDENTIDAD FEMENINA EN PSICOSIS (A. HITCHCOCK, 1960)
}

\author{
THE CRANE PERSPECTIVE. \\ THE CRISIS OF FEMALE IDENTITY IN HITCHCOCK'S PSYCHO
}

\author{
Laura ANTÓN \\ Universidad Rey Juan Carlos
}

Recibido: 30/12/2015

Aceptado: 29/03/2016

\section{Resumen}

Tomando como punto de partida la trama de lectura que se ha constituido en torno a este célebre film del cine de terror moderno, el presente análisis textual propone un estudio global de su discurso sobre la mujer. Trata de recuperar lo que ha sido eclipsado por otras cuestiones. Más allá de Norman y el desdoblamiento madre-(monstruo)hijo, en la segunda parte del film aparece otro personaje femenino, la otra hermana Crane. ¿Qué simboliza esta (doble) perspectiva Crane? La hipótesis que se maneja para responder a esta cuestión es que en este texto, representativo de la crisis de la narrativa audiovisual de Hollywood, el significante fílmico de la feminidad se somete a un desdoblamiento simbólico propuesto por Marion y Lila. Mediante esta estrategia narrativa con la que se ha significado la identidad, el discurso del film dramatiza a la manera moderna, de forma excesiva, una crisis femenina, en un periodo histórico, el inicio de la década de los sesenta, desafiante en relación con el rol cultural que se esperaba de la mujer en la sociedad norteamericana.

Palabras clave: lectura, narrativa audiovisual, identidad, perspectiva, mujer investigadora.

\begin{abstract}
Taking as a starting point reading built around this famous film of the modern horror film, this analysis suggests an overall reading of his discourse about the woman. Try
\end{abstract}


to recover what we have become accustomed to forget, or at best, to score because it has been overshadowed by other issues. And is that beyond Norman and splitting monster mother-son, in the second part of the film another female character, the other sister Crane appears. What symbolizes this (double) perspective Crane? The main hypothesis management to answer this question is that this representative text of the discourse audiovisual crisis Hollywood, the film signifier of femininity undergoing a symbolic split proposed by Marion and Lila. Through this narrative strategy that has meant the question of identity, discourse of the film dramatizes the modern way, excessively, an identity crisis of women in a historical period, the beginning of the sixties, significant changes to the cultural role expected of women in American society.

Keywords: reading, audiovisual narrative, identity, perspective, female investigator. 


\section{INTRODUCCIÓN ${ }^{1}$}

La presente lectura cultural de Psicosis encuentra su origen en un estudio anterior sobre una narrativa femenina, «El drama pasional de la mujer investigadora. Un arquetipo femenino de la crisis» (Antón 2014). Allí, Psicosis fue convocado por la referencia postmoderna producida durante el trayecto de Clarice Starling (El silencio de los corderos, Demme, 1991). Ahora, nuestra intención es regresar al que se ha definido como «el film más oscuro de Hitchcock» (Bellour 292) con el fin de estudiar qué se ofrece en su narrativa, señalada como hito ineludible de la modernidad, sobre la construcción cultural de la feminidad. Cómo se constituye la mujer en este relato de estructura quebrada, por el asesinato y «caída» de la (anti)heroína-estrella bien avanzada la acción ${ }^{2}$, que pondría en crisis los fundamentos estéticos del discurso institucional.

Se ha olvidado que el origen de esta quiebra del relato radica en el protagonismo en la acción de un subversivo punto de vista femenino, de una amante y ladrona, que a pesar de ser brutalmente cegado no podrá invisibilizarse. Es significativo que ese tiempo de reflexión metaficcional que acontece en el corazón del relato y estrechamente asociado con la cuestión de la mirada (femenina) remita al plano detalle del ojo con el que se inicia el surrealista Un perro andaluz (Buñuel, 1929), el que fuera uno de los films favoritos de Hitchcock (Spoto 2004). En efecto: «Lo que Buñuel-Dalí mostraban al principio de su Chien andalou, el ojo rasgado, Hitchcock lo consumaba a mitad de película» (Trías 116). La lectura de Talens en El ojo tachado incidió en que esa perspectiva se corresponde, y no por casualidad, con un punto de vista femenino: el corte del ojo femenino estaría obligando a la mujer a liberarse de un punto de vista que no le corresponde (110 y ss.). Precisamente es ese discurso metaficcional sobre la perspectiva de la mujer el que refuerza el

1. Proyecto de investigación: «Imaginarios de la crisis: las representaciones audiovisuales de la quiebra económica, social y geopolítica (1929-2012)».

2. El recordado plano detalle del ojo de Marion se sitúa en el minuto 47 del film. La muerte de la estrella fue uno de los aspectos de la estructura del film más resaltados por Hitchcock y la crítica. Según el autor, su objetivo fue sorprender al público (Truffaut 297). 
diálogo intertextual producido entre ambos films. Como en Un perro andaluz -ni siquiera el autor logrará tachar el deseo de la mujer que reaparecerá «Huit ans après...» utilizando un extraño súper poder asociado a su mirada-, en Psicosis, el movimiento de cámara autónomo que deriva del plano detalle del ojo abierto de Marion, encarna de manera fantasmal, la fantasía del personaje. Como han señalado en su estudio del film, Benavídez y Santoro: «el cuerpo de Marion sin vida tiene una fuerte incidencia en el film» (cit. por Russo 130).

La modernidad estética del film más popular de Hitchcock se asocia también con la especial visibilidad que la estrategia retórica del doble acoge en su discurso. Definida como «a tour de force of doubling strategies» (Allen 195), en Psicosis, además de quebrada, la estructura del relato es especular. El significante cultural mediante el cual se dramatiza, y significa, el asunto de la identidad en los universos de ficción (Antón 2013) adquiere un relieve especial en la doble personalidad de Norman, y conforma la perspectiva Crane, constituida por la acción de las dos hermanas de Phoenix, Marion y Lila, que detentan el protagonismo en tramos relevantes de la temporalidad del relato, en las secuencias clímax de su primera y segunda parte, un desdoblamiento femenino que se evidencia, aún más, en la novela (Bloch 1959). ¿Qué simboliza esta (doble) perspectiva Crane?

En su estudio del film, Barbara Creed (1993) se detiene en el peculiar y doble significado del apellido de las hermanas de Phoenix. De una parte, Crane es el nombre con el que se conoce a un ave zancuda de largo cuello que le proporciona una vista privilegiada de su hábitat. Además, en inglés, Crane significa «grúa». Un significado que Bellour asocia con el dispositivo de representación fílmico puesto que la cámara adquiere un punto de vista omnisciente (310). Ambas definiciones guardan una estrecha conexión con la noción de perspectiva (del latín, "per-specio»: «mirar a través de»). Una cuestión que no debe perderse de vista en el estudio de la imagen audiovisual, pues es el significante sobre el que se asienta la perspectiva narrativa del plano y el eje del deseo que atraviesa el relato.

La hipótesis principal que se maneja para responder a la cuestión que abre esta doble perspectiva Crane es que, en este discurso emblemático de una narrativa en crisis, la estrategia simbólica del desdoblamiento dramatiza de forma excesiva, a la manera moderna, una crisis de la idea de la feminidad, que se escenifica como un tortuoso trayecto. Aquí, la redefinición cultural a la que se somete el concepto mujer se manifiesta a través de la resistencia (Modleski) que expone el itinerario femenino a inscribirse en la definición social de mujer del sistema retratado, un sistema en crisis, donde la histeria de la vida cotidiana capitalista se enfrenta a su reverso psicótico (Bellour; Žižek 2001). 
Es preciso recordar que es la temporalidad de este trayecto femenino la que está quebrada y desdoblada, seccionando la estructura clásica del relato. Es decir, que esa marca de ruptura donde se ha concentrado el carácter moderno del film se relaciona con el concepto de feminidad que, de manera revisionista, se deconstruye y reconstruye en este texto. En la primera parte, el trayecto de la mujer se presenta como un viaje pulsional, fuera de la ley, que acabará con un castigo mortal. El deseo femenino de ser feliz se transforma así en una terrorífica fantasía sadomasoquista. Más adelante, el trayecto de Lila es impulsado, sin embargo, por una forma de conocimiento pasional sobre el paradero de su hermana. Ambas se relacionan con el arquetipo femenino de la madre, el tercer componente del triángulo de la feminidad representado en el film y sometido también a un siniestro desdoblamiento. La madre, que vigila la conducta sexual de sus hijas, obtiene su contrafigura en una madre cruel, la madre de Norman. Sin embargo, la actitud investigadora de Lila le permitirá retomar la perspectiva de su hermana para internarse en la casa gótica donde logrará ver, conocer, sin perder la vida, el gran misterio en torno al que se construye la estrategia de suspense del film: el rostro, la identidad, de la señora Bates.

\subsection{Construyendo otro sentido}

Precisamente, son los aspectos centrales que el proceso de lectura del film ha ido destacando desde su estreno los que reclaman una reflexión sobre esta cuestión femenina. El acto de lectura dirigido a apropiarse del film como objeto cultural, es decir, con el que un colectivo llega a sentirse identificado, no consiste tanto en obtener un sentido único que permanezca inalterable durmiendo el sueño de los justos como en ir delineando -la lectura es un proceso temporal- a través de ese denso laberinto expresivo que ofrecen las obras maestras, un posible itinerario que nos ayude a entender cómo funciona un artefacto en permanente (re-)construcción cultural.

Psicosis se ha convertido en un referente indiscutible de la modernidad fílmica, contribuyó a la renovación narrativa que se había venido produciendo en la práctica de Hollywood con el film noir (1941-1958). Es uno de los arriesgados films con los que el arte del cine se deja ver como lenguaje y explora nuevas formas expresivas. Buena parte de la reflexión discursiva que pone en escena recae sobre la perspectiva narrativa del plano. En relación a este asunto, la lectura habitual ha destacado cómo el crimen secciona el relato en dos partes, si no independientes bien diferenciadas, que identifica con dos historias: la de Marion y la de Norman (Bellour; Douchet; Žižek 1988). Es decir que, atendiendo a esta interpretación, el asesinato de Marion simbolizaría la represión del deseo femenino en el texto (Kuhn 119). 
En «Psychose, névrose, perversion» (1979), Bellour destacó la oscuridad del film: "Obscur parce que jamais dans aucun de ses films la nuit n'a paru aussi sombre, le jour aussi crépusculaire» (292). Esta densa y literal oscuridad en la que se sume el universo diegético es, además, según el estudioso francés, una oscuridad retórica, indicativa de que el film contraviene el modelo clásico, e incluso ese modelo más singular que es el sistema Hitchcock. Esta oscura modernidad del film puede localizarse también en el uso de la perspectiva narrativa. En este estudio se ha intentado resaltar la idea de que la segunda parte del relato no está contada únicamente desde la perspectiva de Norman, como se ha indicado con anterioridad, sino que se propone como una compleja trama de perspectivas que pone en escena, como objeto reflexivo, la cuestión de la perspectiva del plano y el proceso de identificación resultante. A diferencia de lo ocurrido en la primera parte, Norman compartirá su punto de vista con el resto de los personajes, que realizan una investigación.

De acuerdo con Žižek: «El proceso de identificación y su subversión constituyen la llave del film» (2001, 186). El deseo de saber de Lila reactiva el protagonismo femenino cegado en la primera parte, logra vencer las diversas resistencias que se le plantean como mujer investigadora: la profesión de Arbogast, el rol que la sociedad encomienda a Sam y no a una mujer, del representante legal de la ley, etc. Desde esta otra perspectiva Crane, la segunda parte del film, más que entenderse como la historia de Norman o de la madre cruel (Creed 1993), puede leerse como el trayecto definido por las dificultades que Lila debe sortear para convertirse en la mujer investigadora y heroína del relato. Bellour sugirió esta misma idea aunque su lectura se centre, una vez más, en las historias de Marion y Norman quien, según el estudioso francés, se constituirá en el nuevo (anti)héroe del relato, transformándose la neurosis femenina en una psicosis masculina, las dos estructuras psíquicas que percibe en el film (294 y ss.).

\subsection{El desplazamiento de la mirada hacia lo femenino}

En relación al estudio de la identidad o subjetividad femenina en el discurso audiovisual, esta obra de madurez del estilo Hitchcock es especialmente relevante. Como se sabe, la obra de este popular autor ha suscitado un creciente interés en relación con el estudio de la imagen de la mujer. Esta curiosidad se ha centrado en aspectos que van más allá de la relación que el artista mantuvo con sus actrices rubias, de la que Las damas de Hitchcock (Spoto 2008) constituye una muestra ejemplar, donde se abona la idea de un artista brillante pero misógino y sádico con sus actrices, y con fuertes problemas para comunicarse con los demás. Además, el estudio de la cuestión femenina, de las damas en 
el cine de Hitchcock, ha obtenido un lugar destacado en el desarrollo de la teoría feminista del cine, es decir, en el tipo de análisis fílmico que se propone estudiar cómo se representa el significante mujer con el objetivo de valorar si dicha representación supone un avance progresista para las mujeres reales. En Hitchcock et la théorie féministe. Les femmes qui en savaient trop (1988), la profesora de literatura comparada Tania Modleski situó los films del mago del suspense en «el corazón de la primera formulación de una teoría feminista del cine» (9). Su análisis se estructura en torno al análisis de una serie de films (Rebeca, Encadenados, La ventana indiscreta, Vértigo...) de la que significativamente no forma parte Psicosis, aunque sí realice algunas referencias. Así, por ejemplo, subraya cómo las críticas masculinas del film habían coincidido en reprimir la feminidad representada, pues destacaron que se trataba de un film que castigaba al espectador por su deseo ilícito de voyeur, sin tener en cuenta el hecho de que en el film no solo las mujeres son objeto de la mirada de los hombres, sino que además son ellas las más severamente castigadas: en la detención de la cámara sobre el ojo ciego de Marion, Lila es la encargada de tener una horrible visión de la madre, se muestra el cadáver de una mujer (29).

En el capítulo introductorio, «Hitchcock, le féminisme et l'incoscient patriarcal», Modleski inicia su análisis marcando una distancia en relación al influyente artículo de la estudiosa británica Laura Mulvey, «Placer visual y cine narrativo» (1975), que había propuesto la obra del mago del suspense -cita La ventana indiscreta (1954), Vértigo (1958) y Marnie, la ladrona (16 y ss.)- como modelo demostrativo de que en el cine clásico de Hollywood la mujer se representa como objeto pasivo del voyeurismo y el sadismo masculinos. A diferencia de Mulvey, según la cual la concepción de un nuevo «lenguaje del deseo», no patriarcal, pasa por la destrucción del placer narrativo, Modleski opta por una posición ambivalente, pues «les femmes chez Hitchcock» ofrecen en sus trayectos una resistencia a la asimilación patriarcal, reveladora de problemas de identidad femeninos (13). Muestra así su desacuerdo con la idea de Bellour de que en el relato clásico se desarrolla un problema de identidad masculino, desarrollado a través de una trama edípica masculina (75).

En «The Birds: a Mother's Love» (1982), Margaret M. Hortwitz ya había desplazado el interés de la lectura dominante sobre este film, centrada en la representación de la violencia masculina contra la mujer, hacia el conflicto producido entre los personajes femeninos, especialmente entre Melanie, la heroína, y Lydia, la madre de Mitch. Además, plantea una hipótesis muy interesante: la centralidad ocupada por la figura materna permitiría considerar 
Los pájaros (1963) como integrante de una trilogía, junto a Psicosis y Marnie, la ladrona (1964). En efecto, en estas tres películas el drama de la mujer se localiza en el deseo femenino, de Marion, Melanie y Marnie ${ }^{3}$, por el Otro masculino, que será violentado por su relación con la madre.

En «The Castrating Mother: Psycho» (1993), Creed reivindicó una lectura de Psicosis desde una perspectiva femenina, interesándose por el estudio de la historia de la madre, a pesar de que, como reconoce, este personaje posea un estatuto imaginario-fantaseado en el texto.

\section{LA CONSTRUCCIÓN DE LOS ARQUETIPOS FEMENINOS}

El dualismo que atraviesa el film se actualiza en el que sin duda es uno de sus rasgos discursivos más destacables, la relación tradición-modernidad. Entendida de una manera conflictiva, ésta se expresa mediante una confrontación topográfica: la ciudad de Phoenix se opone a las afueras de Fairvale donde se sitúa el motel Bates que, a su vez, contrasta con la casa gótica donde reside la severa madre. Este conflicto visual queda establecido a través de la horizontalidad del motel y la verticalidad de la casa Bates. Un contraste de líneas que, según Hitchcock, fue «nuestra composición» (Truffaut 236), y que recorre buena parte del film (ver Kolker 206-256). Este mismo conflicto se inscribe en la construcción de los arquetipos femeninos, y en su relación con los masculinos, con el que se revisan los fundamentos de la narrativa clásica. En este itinerario de una identidad femenina en crisis se produce una tensa confrontación de arquetipos femeninos. Patrones específicos de la narrativa clásica como son la mujer madre y víctima se enfrentan de manera conflictiva con otros modernos, como la femme fatale y la mujer investigadora.

1) Así, y aunque no sea evidente a primera vista, el personaje de Marion mantiene una fuerte analogía con la femme fatale, el arquetipo moderno que en film noir (1941-1958) se confronta con el de la mujer esposa y madre. Su protagonismo en la acción, atractivo sexual y una conducta en contra del rol social asignado a la mujer, que marcará a modo de heroína trágica su destino fatal, permiten que se posicione en el imaginario masculino de la ficción negra. No obstante, Marion es una femme fatale atípica, puesto que no aparece en escena desde el punto de vista masculino. Es presentada no como objeto sino como sujeto del deseo hacia el hombre. Ya se sabe: «In the classical narrative cinema, to see is to desire» (Williams 61)

3. En su análisis de Los pájaros, Camille Paglia indica que Marnie resulta de la fusión de Marion y Melanie (118). En Marnie, en una de las tarjetas de identificación de la mujer puede leerse «Marion Holland». 
Es significativo que, a diferencia de la novela en la que se inspiró el film (Bloch 1959) que comienza con una perspectiva omnisciente: «Norman Bates oyó el ruido y se estremeció», la trama se inicie con la exposición del drama de Marion, y sea ese deseo femenino el que «conduzca» la acción durante cerca de un tercio de la duración del film en un singular tratamiento audiovisual. La inicial vista de pájaro localiza la historia en unas precisas coordenadas espaciales y temporales -«Phoenix, Arizona», «Friday, December Eleventh», «Two Forty-Three»-, antes de que ese punto de vista omnisciente se cuele por la ventana de la habitación del hotel donde se encuentra una pareja de amantes que no puede casarse, como prescribe el sistema, debido a sus problemas económicos. El movimiento de cámara enfatiza la idea de que el encuentro sexual es furtivo y coloca al espectador en la posición clásica de sujeto voyeur. Así, el acto de la escritura inicia una reflexión sobre la mirada que puntúa la temporalidad del relato e incluso cuestiona su estructura. Precisamente, la lectura sobre la crisis del discurso clásico que se produce en la obra de Hitchcock se ha concentrado en torno a la cuestión sobre cómo se configura el acto de la mirada (Castro de Paz 40 y ss; González Requena).

Ya en esta primera escena, la perspectiva narrativa dominante se identifica con la mujer, como prefigura el plano con el que se presenta a la pareja de amantes, allí donde se estabiliza el complejo movimiento de cámara inicial [imagen 1]. La cámara se sitúa a la altura de los ojos de la mujer. Marion, tumbada en la cama, mira al hombre, de pie, cuyo torso es, significativamente, cortado por el encuadre. El drama femenino que aquí se configura es su condición de mujer que actúa al margen de la norma social, no puede casarse con el hombre al que ama (el zoom in sobre el rostro-mirada fuera de campo de Marion, cuando Sam sale de campo, subraya esta idea). Como acertadamente señaló Creed (1993), esa norma social represora se identifica, ya en

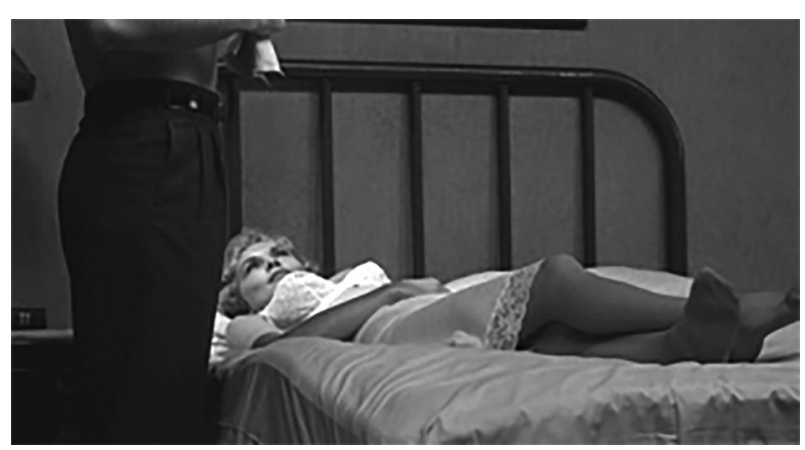

Imagen 1 .

Feminismo/s 27, junio 2016, pp. 53-78 
esta primera escena mediante un diálogo, con la figura materna, a la que se le asigna el rol de guardiana de la moral familiar:

-Marion: Podemos seguir viéndonos, incluso comer juntos. Pero respetablemente, en mi casa y con el retrato de mi madre en la pared y mi hermana ayudándome a preparar una comida para tres.

-Sam: Y después de comer, enviamos a tu hermana al cine y le damos la vuelta al retrato.

-Marion: ¡Sam!

La siguiente escena, en la oficina de la inmobiliaria donde Marion trabaja como secretaria, subraya este problema económico. Aquí se confirma que es solo una mujer independiente, trabajadora, en apariencia. Precisamente será en la esfera laboral del personaje donde se confronte, en plano/contraplano, con el modelo social de mujer, Caroline [imágenes 2 y 3], y con un adinerado cliente (padre), en el que se anuda de nuevo el conflicto tradición-modernidad económica (viste un traje y lleva un sombrero de cowboy), y que indica el

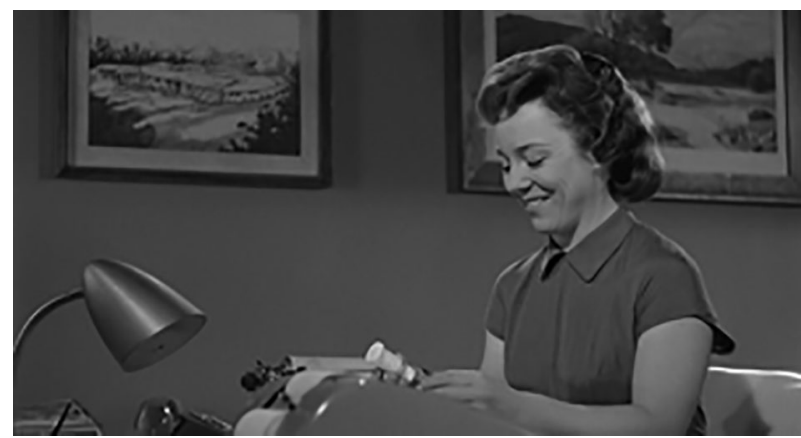

Imagen 2.

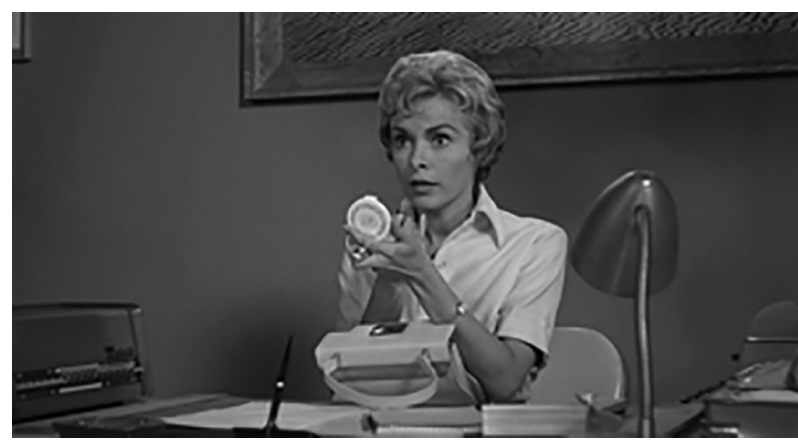

Imagen 3.

Feminismo/s 27, junio 2016, pp. 53-78 
objeto, una transacción económica, sobre el que se mide el grado de felicidad en el sistema social retratado. Bellour y Žižek (2001) señalaron la analogía entre el cameo de Hitchcock, en el plano con el que se inicia esta segunda escena, con este padre de la novia. Una relación realzada por el hecho de que el papel de la otra secretaria, Caroline, sea interpretado por la hija del cineasta, Pat Hitchcock ${ }^{4}$. Esta peculiar forma de aparecer en sus películas, desde El enemigo de las rubias (1927), además de constituir una especie de sello autoral se fue ubicando, según Bellour, en un determinado momento del film donde se condensa «el deseo del film» (278).

Desde el inicio, seguimos el trayecto de una mujer que mira y a la que miran los hombres (Sam, el cowboy moderno en la segunda escena, su jefe en el semáforo, el policía, los hombres de la tienda donde cambia de coche...). Conforme avance el film, el tratamiento audiovisual de esta mirada masculina hacia la mujer se torna inquietante hasta llegar al motel Bates. Su punto de vista se cegará en la que sin duda es una de las escenas más famosas del cine. Marion acaba siendo una mujer víctima, y es irónico que sea así, justo cuando muestra arrepentimiento por el robo de los 40.000 dólares, tras su conversación con Norman.

2) La señora Bates se identifica con el arquetipo de la mujer madre en una versión monstruosa (Creed 1993). En «la madre de Norman» se combinan la mujer madre y la femme fatale, dos arquetipos que se han definido como masculinistas, es decir, que tienen una fuerte presencia en las fantasías del imaginario masculino transmitido a través de los productos culturales. Como indican, al final, las siniestras cuencas de sus ojos, su punto de vista está cegado en el universo del film. A diferencia de Marion, de la perspectiva Crane, su perspectiva no se mostrará. Su estatuto es similar al de Rebeca (1940) ${ }^{5}$, imaginario. Esta ausencia de perspectiva la relaciona con una concepción clásica, y masculina, de la alteridad, en su doble condición: monstruo y mujer.

3) Lila representa el rol de la mujer investigadora. Invierte el trayecto de su hermana, pues la inicial mujer doméstica (da) con la que Marion se identifica en la primera escena llegará a ser una mujer investigadora, cuyo deseo de saber tendrá como escenario la casa gótica de la madre cruel. A diferencia de su hermana, Lila tendrá que compartir el protagonismo con otros hombres y sus fantasías, la madre monstruo de Norman, hasta llegar a esa secuencia clímax, en la que ya, por fin, y alejada del rol de mujer doméstica se coloca

4. Según la jefa de vestuario, Rita Riggs, en Psicosis decidió aparecer junto a su hija por una cuestión sentimental (Rebello 128).

5. En «La femme et le labyrinthe. Rebeca», Modlesky sigue la idea de R. Durgnat y sostiene la hipótesis de que la mujer sin nombre forma parte de una trama edípica, identitaria. 
en el papel de la mujer investigadora para confrontarse audiovisualmente, en plano/contraplano, con la madre fantaseada.

La idea de la crisis de la mujer no sólo se expresa mediante esta trama conflictiva de modelos de mujer, sino también con la deformación expresionista a la que se ofrece el arquetipo de la madre (monstruo), y en una revisión característica del neo-noir que aún estaba por venir. Así, la figura del hombre investigador es sustituida por la mujer investigadora que logra vencer el destino trágico de la femme fatale.

No se puede obviar que este cuestionamiento de la subjetividad femenina, realzado por rasgos estéticos del expresionismo, se produjo en un marco histórico de desafiantes cambios para el rol sociocultural que se esperaba de la mujer. El inicio de la década de los sesenta coincide con una especial actividad para el feminismo. Un periodo que se conoce como la segunda ola feminista, y cuyo su origen suele situarse en Estados Unidos ${ }^{6}$. Aunque su temporalidad se inscriba dentro de unos márgenes que abarcan desde los años sesenta hasta el final de la década de los setenta, la (im)pertinencia de su espíritu reivindicativo sobrevive en la actualidad. Si la primera ola feminista, localizada preferentemente en Estados Unidos, Francia e Inglaterra a lo largo del siglo XIX y principios del XX, se caracterizó por el acceso de la mujer a derechos fundamentales tales como los de propiedad y de voto, esta segunda ola se marcará como horizonte, a día de hoy todavía lejano ${ }^{7}$, la conquista de la igualdad en la actividad laboral y la reivindicación de la capacidad de elección, la emergencia de la voz femenina, en las esferas de la sexualidad y la reproducción. Este ánimo reivindicativo que recorre la segunda mitad del siglo XX alcanzando al presente siglo XXI ha marcado el trayecto vital de la mujer moderna. En La mujer cuarteada, Gil Calvo señala que la característica sociológica de la mujer moderna es la dualidad mujer doméstica-mujer trabajadora. Esta trayectoria dualista de la vida, que acompaña a la mujer investigadora (Antón 2014), marca una asimetría en relación con la de ser hombre. Asimismo, interpreta

6. Karen Offen ha cuestionado la temporalidad ofrecida por esta metáfora de las olas, pues no resulta adecuada para entender el fenómeno del feminismo que precede en varios siglos a los movimientos organizados (61).

7. En España, durante la crisis económica se ha producido un retroceso en la conquista de estos derechos. No sólo se ha cuestionado la capacidad de elección de la mujer en la reproducción, sino que en este mismo periodo ha aumentado la brecha salarial de género. En 2013, la hora trabajada por una mujer fue un 19,3\% más económica que la de un hombre (Bolaños). Esta brecha salarial de género se dejó notar en los honorarios del elenco artístico de Psicosis. Janet Leigh (Marion Crane) recibió un salario de 25000 dólares, por seis semanas de trabajo, frente a los 30000 de John Gabin (Sam Loomis). (ver Rebello 82 y ss.). 
esta definición social de la mujer como el drama de la mujer moderna pues imposibilita la integridad de la trayectoria femenina.

No creo que sea una casualidad que esta crisis de identidad que precipita el viaje femenino en Psicosis pueda percibirse, asimismo, en otros films emblemáticos de la modernidad, que vienen produciéndose al otro lado del Atlántico y que la historiografía ha tomado como casos modélicos de la ruptura de la narrativa institucional, cuestionada por la expresión del autordirector. Es el caso de Estrómboli (Rossellini, 1950), cuyo final abierto puede interpretarse como una inquietante metáfora del imaginario femenino de la modernidad. La mujer investigadora de Recuerda (1945) y la espía, esposa y amante en Encadenados (1946) se transforma aquí en una exiliada lituana, Karin, que consigue salir de un campo de refugiadas gracias a su matrimonio con un italiano, con el que viajará a la isla Estrómboli. El emocionante final abierto puede interpretarse como símbolo del drama (del deseo femenino) que supone otra forma de ser mujer en la posguerra. Cerca de la cumbre del volcán en erupción que corona la isla experimenta su soledad y reivindica su libertad, y apoyo para ser autosuficiente. Asimismo, en La aventura (Antonioni, 1960), Anna desaparecerá en el minuto 27 del film tras haber cuestionado el rol social de mujer esposa. Y en Al final de la escapada (Godard, 1960), el objeto de deseo de Michelle Poicard, Patricia, se transforma en una femme fatale que reivindica el protagonismo femenino, en el último plano del film, con una desafiante mirada a cámara.

Además de las rupturas formales que habitualmente se han señalado en relación con las coordenadas espacio-temporales del relato clásico, en esta narrativa audiovisual en crisis, moderna, se instala una reflexión sobre la construcción del significante mujer en el discurso institucional, revelando que otros discursos femeninos son posibles. Durante sus respectivos trayectos, Marion y Lila, también se confrontan con definiciones femeninas propias del american way of life: la mujer esposa y madre.

\subsection{El trayecto de la fantasía femenina}

La transformación del estilo realista del inicio del relato se producirá durante el viaje femenino. En este tramo de tránsito, se expone la crisis de identidad de la mujer. Marion conduce desde la ciudad de Phoenix a Fairvale en busca de Sam con los cuarenta mil dólares. De forma progresiva, algunos rasgos estéticos del estilo expresionista, ligado al estilo Hitchoock ${ }^{8}$, se apoderan de

8. En su estudio de la ironía romántica como elemento de cohesión en la obra del cineasta inglés, Allen dedica un capítulo a la influencia del expresionismo presente en la figura del doble y sus motivos visuales, la escalera, la espiral, etc.

Feminismo/s 27, junio 2016, pp. 53-78 


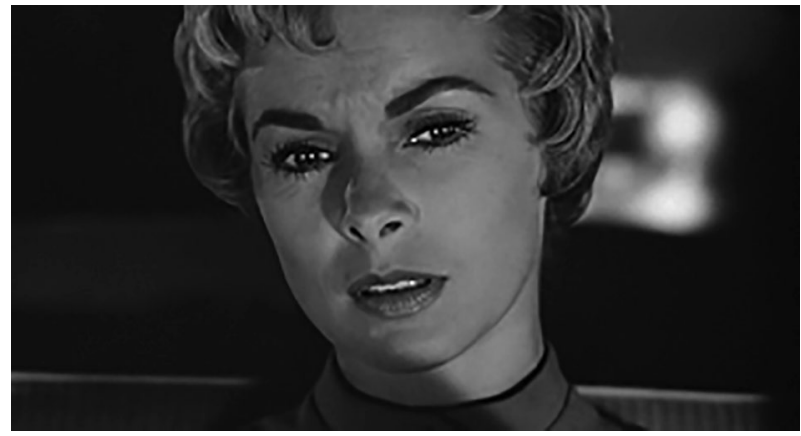

Imagen 4.

la puesta en escena de este viaje femenino fuera de la ley. Este cambio es anotado por la temporalidad. Así, la precisión espacio-temporal del inicio dará paso a una temporalidad más abstracta e incluso confusa. Ahora comienzan a sucederse las elipsis narrativas que permiten el paso del día a la noche, contribuyendo a reforzar la organización dualista de los significantes. Este escenario nocturno favorece la aparición de sombras que deforman el espacio representado e inciden en el drama femenino.

Además de estas marcas expresionistas, prolifera el punto de vista subjetivo, articulado por la figura de plano/contraplano, que enfatiza un modo de focalización del relato interno. El primer plano de la actriz, de connotaciones psicológicas, y su voz en off, acompañada de una inquietante música extradiegética, determinan que sobresalga, aún más, la definición subjetiva [imagen 4]. El carácter fantaseado de este viaje femenino comienza a subrayarse cuando conduce y piensa en lo que le dirá su novio. Una acción que permite leer el encuentro inesperado con su jefe, en el semáforo, y su inquietante mirada de extrañamiento como una extensión de la fantasía femenina. Más adelante, esta voz interior de la mujer alcanzará a los hombres de la tienda donde ha cambiado de coche, a su jefe, su compañera de trabajo y el millonario cuando se enteren de que ha huido con el dinero. Todos estos rasgos narrativos permiten leer este cambio de rumbo estético del relato como la puesta en escena de la fantasía femenina. Es decir, según la definición de fantasía de Laplanche y Pontalis, como «la puesta en escena de un deseo» femenino (cit. por Creed 1988, 99).

\subsection{Significantes audiovisuales de la crisis de identidad}

Los diversos significantes audiovisuales que aparecen en el trayecto de Marion apuntan a una crisis de la subjetividad femenina. No se propone ya la 


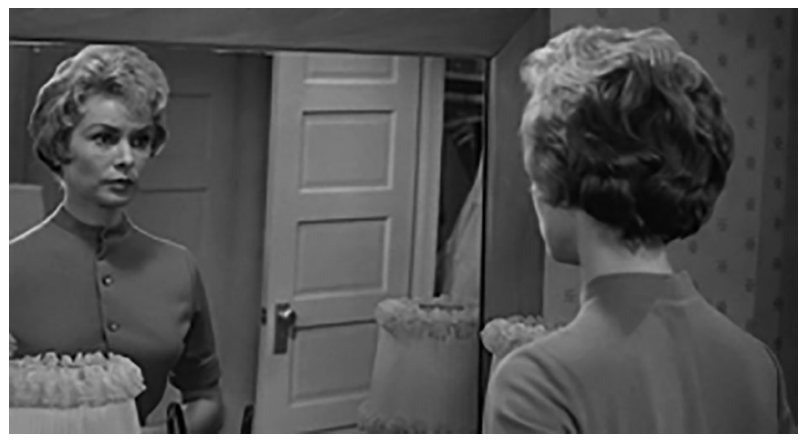

Imagen 5.

narrativa de la masculinidad en crisis, como en Vértigo, sino de la crisis de la mujer. Esta idea se enfatiza en la primera escena a través de la crisis de una pareja de amantes. Y, un poco más adelante, surgirán sus principales significantes audiovisuales. Como motivo visual, el espejo aparece por primera vez en la tercera escena, en la habitación de Marion. La reflexión sobre su identidad, de mujer trabajadora, adaptada al sistema social, a ladrona, se muestra mediante el reflejo especular que duplica su figura [imagen 5]. Este drama femenino se amplía en distintos tiempos significativos del viaje. La mirada fuera de campo de la mujer que conduce la acción del relato, acompañada de la misma música extradiegética que se amplificará en la escena más famosa del film, prefigura un objeto de deseo que inquieta, y que se aloja en los contraplanos. Es el temor que la mirada masculina (de su jefe, en el semáforo; del polícia; de los hombres, en la tienda de automóviles) genera en una mujer que huye [imagen 6].

La fantasía femenina continúa su trayecto, otra vez durante la noche, hasta llegar al motel Bates. El cartel de carretera surge, por primera vez, desde

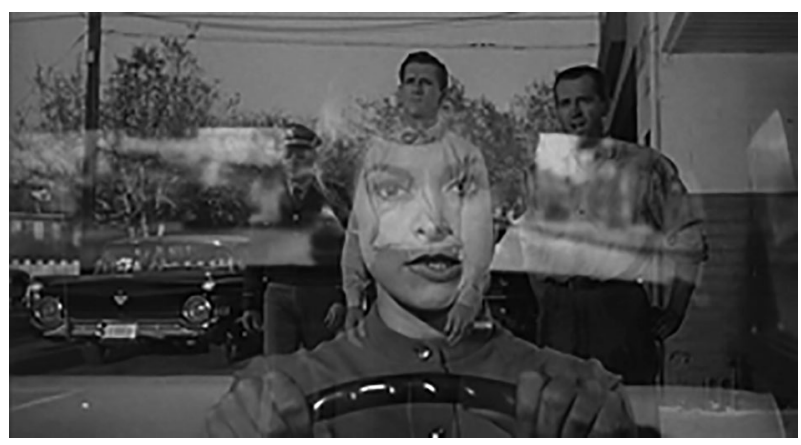

Imagen 6. 


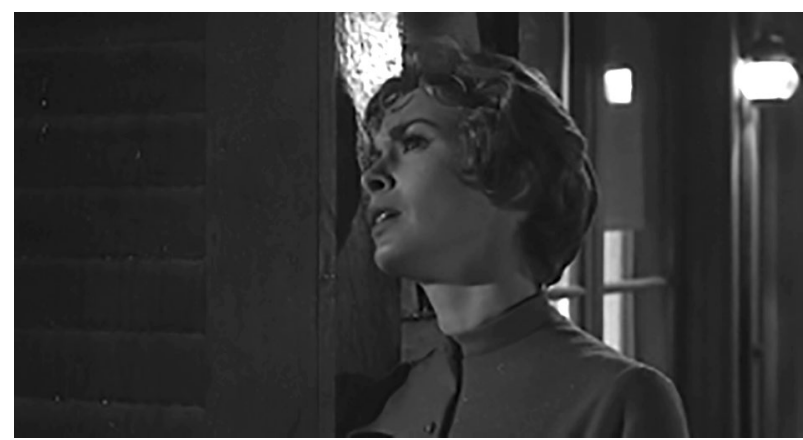

Imagen 7.

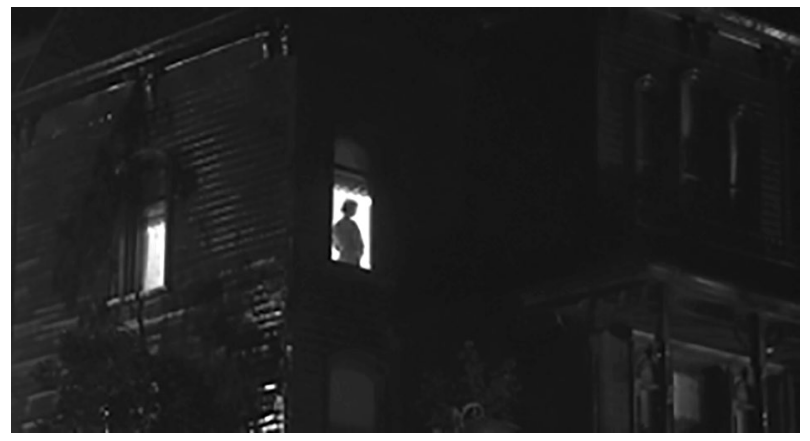

Imagen 8.

el punto de vista de Marion, en este viaje que parece estar configurado por el acto de la mirada (deseo) femenina y sus obstáculos (la oscuridad, los hombres, el deslumbramiento de los faros de los coches, la lluvia...). El cartel del motel parece abrir de negro, de la oscuridad en la que se ha sumido la visión de Marion. Un fundido a negro subjetivo que contrasta con el único fundido a negro, objetivo, que se ha utilizado con anterioridad para simbolizar el paso del tiempo, del día a la noche, subraya la desorientación de la mujer en una noche oscura y lluviosa, y refuerza, todavía más, esa escenificación del deseo femenino. Un poco más adelante, la sombra fantasmal que se perfila en la ventana de la oscura casa de la colina, Norman y los siniestros pájaros disecados que se encuentran en la sala de estar del motel también se presentan visualmente desde la perspectiva femenina [imágenes 7 y 8]. Como se sabe, el motivo de los pájaros, que no aparece en la novela, es una constante en la obra del cineasta británico. Paglia recoge una enumeración (11 y ss.)

La estructura narrativa del film, además de estar atravesada por la dualidad, se organiza en torno a las figuras del triángulo y el espejo. La forma triangular 
se constituye en la primera escena del film (Marion-madre-Sam). Más adelante, esta figura se invierte, generando un efecto siniestro que se apodera del discurso del film, «aquella suerte de sensación de espanto que se adhiere a las cosas conocidas y familiares desde tiempo atrás» y estrechamente asociada con el «asunto» del doble (Freud 1919). La noche sustituye al día, el hotel de la primera escena se transforma en un motel, y la casa materna en una oscura casa gótica habitada por una madre monstruosa, la Sra. Bates. Nada impide entonces que relacionemos esta segunda figura triangular con la fantasía sadomasoquista de Marion. Marion proyecta su deseo pulsional sobre Norman, el hombre fatal que sustituye a Sam, y a la vez simboliza las relaciones fantásticas entre ella y su madre -Bellour y Žižek (1988) indicaron la relación especular «Norman-Marion»-. Y es esa relación de deseo, de Norman hacia Marion, la que es violentada con un cruel asesinato por una madre monstruo.

\section{LA OTRA PERSPECTIVA CRANE}

Desde el interior de la ferretería donde trabaja Sam vemos cómo una mujer, Lila, se baja de un coche. Tiene un extraordinario parecido físico con su hermana, pero a diferencia de ella no conduce. Quiere saber dónde se encuentra su hermana. Ahora su punto de vista será interrumpido de forma violenta -su rostro parece atravesar la cámara- por el del hombre investigador, Arbogast.

A partir de este momento, el rol de la mujer se identifica con la espera. Lila tendrá que esperar a que Arbogast desarrolle su investigación, y más adelante, ante la desaparición del detective, volverá a situarse en este mismo rol, en la ferretería, mientras Sam va a buscar a Arbogast -«Y... ¿qué haré sola?... ¿sentarme a esperar?», pregunta a Sam-. Más adelante, será ella quien tome la iniciativa de ir al motel. Pero, a diferencia de su hermana, Lila no conduce el coche sino que lo hace Sam [imagen 9]. El motivo visual de la mujer

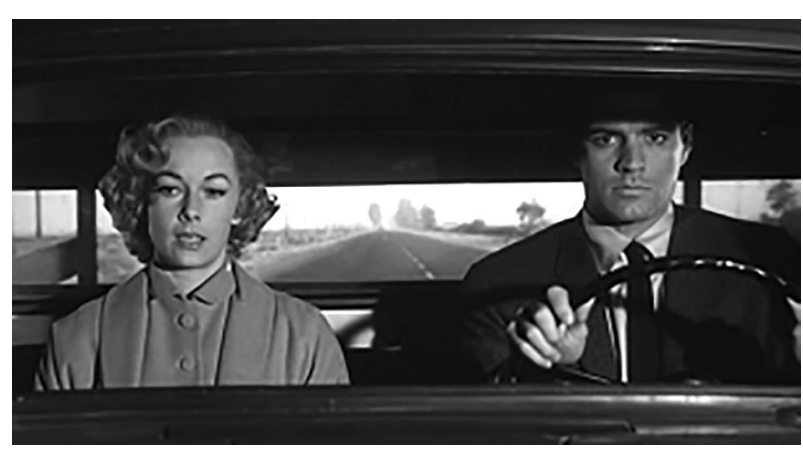

Imagen 9.

Feminismo/s 27, junio 2016, pp. 53-78 
conductora es una metáfora del empoderamiento femenino que adquiere un tratamiento destacado en el cine de Hitchcock. Así, en los dos films posteriores a Psicosis, Los pájaros y Marnie, la ladrona, las heroínas, presentadas como mujeres que desafían la conducta pautada por el sistema social, "conducen» la acción, y en ambos casos acabarán siendo «conducidas» por el hombre, que las ayuda a resolver un problema de identidad que involucra a la figura materna.

Ya en el motel, Lila y Sam se harán pasar por una pareja. Precisamente, esta sujeción de la mujer a la norma social -no conduzcas, no vayas sola a un motel sin la compañía de tu marido,...- permite que se ganen la confianza de Norman y de su madre. Confirman que Marion estuvo en la habitación «1». Será allí, donde se encuentran las imágenes de los dos pájaros en espejo -tras el asesinato de Marion, cuando Norman entra en la habitación, uno de ellos cae al suelo- donde Lila explicará a Sam su intención de hablar con la Sra. Bates.

\subsection{El trayecto de Lila en la casa gótica}

Carol Clover, en Men, Women and Chain Saws. Gender in the Modern Horror Film, encuentra un precedente del Slasher Film en Psicosis. En este subgénero del cine de terror, muy popular en los años 80 y 90, la feminidad es similar a la construida por Psicosis. Una chica atractiva y sexualmente activa se convierte en protagonista de esta trama del horror que la coloca en el rol de víctima. En la secuencia clímax, gracias a su inteligencia, la mujer se revela como heroína y conseguirá vencer a su verdugo. Clover localiza el antecedente de esta Final Girl en el personaje de Lila (39). Sin embargo, expone que la secuencia clímax de Psicosis, si bien está protagonizada por Lila, gira en torno a la revelación de la identidad de Norman. Motivo por el cual, según la estudiosa del Slasher Film, el personaje de Lila no puede llegar a identificarse con el arquetipo de la chica final. La lectura de Žižek (1988) coincide con la de Clover: el trayecto de Lila por la casa gótica está asociado a «la historia de Norman» y no a la de Lila. Cita a Robin Wood (Hitchcock's Films, 1977) que percibe rasgos de la psique de Norman en las distintas alturas de la vieja casa: la habitación de la madre sería el superyó, la planta baja el yo, y el sótano el ello.

En contra de esta lectura, aquí se considera que el trayecto de Lila por la casa-laberinto de la señora Bates está asociado también con la crisis de la subjetividad femenina sobre la que se ha temporalizado el relato. Este trayecto cobra un nuevo sentido si se tiene en cuenta que con este papel la actriz Vera Miles ponía fin a una relación contractual con Hitchcock. La primera colaboración de esta reina de la belleza, fue miss Kansas en 1948, con el cineasta fue 
en el primer episodio de la popular serie televisiva Alfred Hitchcock presenta, Venganza (1955), donde interpreta el papel de una mujer esposa, víctima y loca. Volverá a encarnar un papel similar en Falso Culpable, y cuando estaba todo preparado para trabajar en el rodaje de Vértigo se quedó embarazada, causando el enfado del director, que no entendió que quisiera ser madre interrumpiendo así su trayectoria profesional (Hitchcock; Spoto 2004). Este desencuentro realzó la crisis sobre el concepto de mujer, la dualidad conflictiva de la mujer moderna: mujer trabajadora y mujer madre. Según Miles, fue su rebeldía la que impidió que se amoldara a la imagen de mujer que precisaba Hitchcock: «A lo largo de los años, Hitchcock ha tenido un único tipo de mujer en sus películas: Madeleine Carroll, Ingrid Bergman, Grace Kelly. Yo intenté complacerlo, pero no puede porque era demasiado tozuda y él quería a alguien a quien pudiera moldear» (Spoto 2008, 263).

En este emocionante tramo del relato, la mirada pasional de la mujer investigadora hacia la casa gótica reabre, por fin, el drama femenino [imágenes 10 y 11]. Su punto de vista contrasta, mediante un montaje alternado,

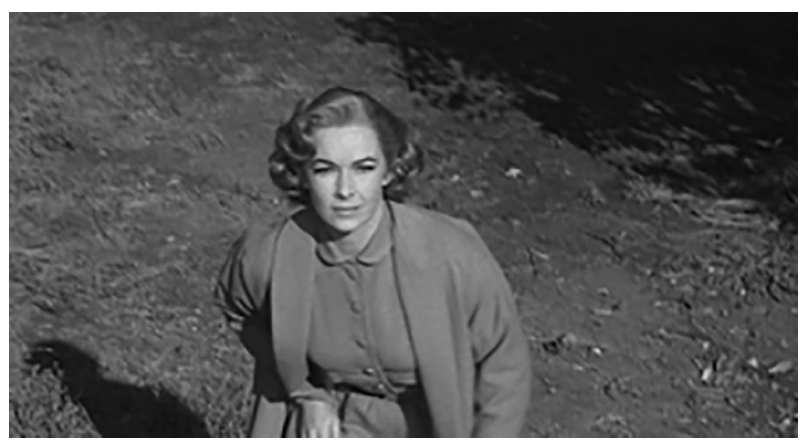

Imagen 10.

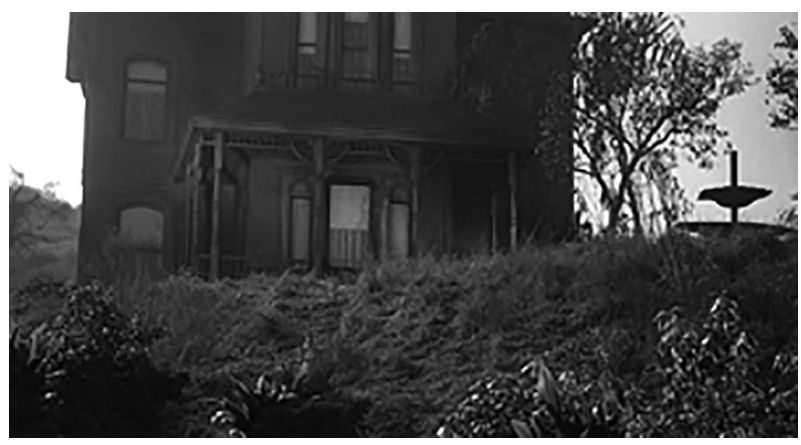

Imagen 11.

Feminismo/s 27, junio 2016, pp. 53-78 


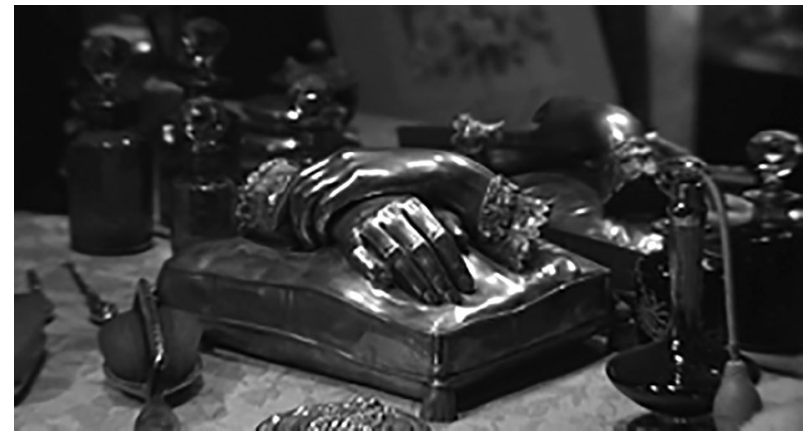

Imagen 12.

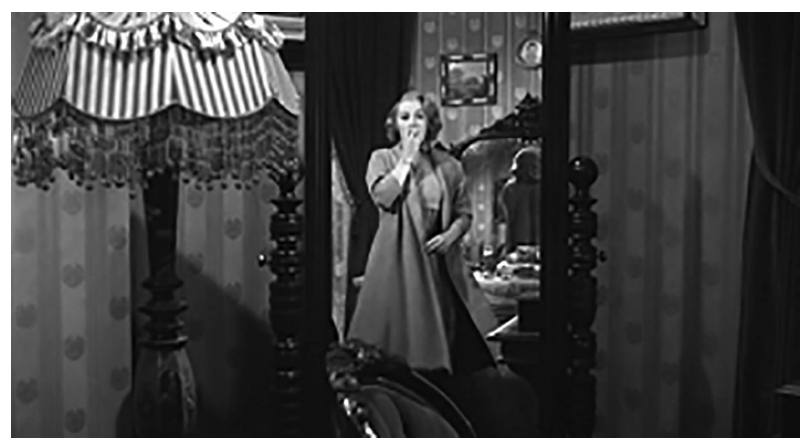

Imagen 13.

con la perspectiva neutra, omnisciente, de la acción de los hombres, Sam y Norman. Ya en el interior de la misteriosa casa, Lila es tocada por la flecha del oscuro Cupido que se sitúa a la entrada. El espacio adquiere rasgos de un laberinto donde la mujer se siente desorientada. Pero a la vez desea saber, al igual que las heroínas góticas o mujeres paranoicas, qué se esconde tras la puerta (Doane). Lo que allí encuentra se relaciona con los Otros, es decir, con su identidad. Así lo indica la reaparición en clave barroca del reflejo especular que asusta a la heroína tras haber visto un extraño, siniestro objeto: unas manos femeninas cruzadas y cortadas, en el tocador de la señora Bates, cuya perspectiva subjetiva, es enfatizada por un rápido zoom in [imágenes 12 y 13].

\subsection{El encuentro con la sombra}

El carácter monstruoso de la madre y su invisibilidad puede relacionarse con una expresión clásica de la alteridad (Cortés), un aspecto irracional con el que, según la significación cultural de la identidad, el héroe y la heroína 


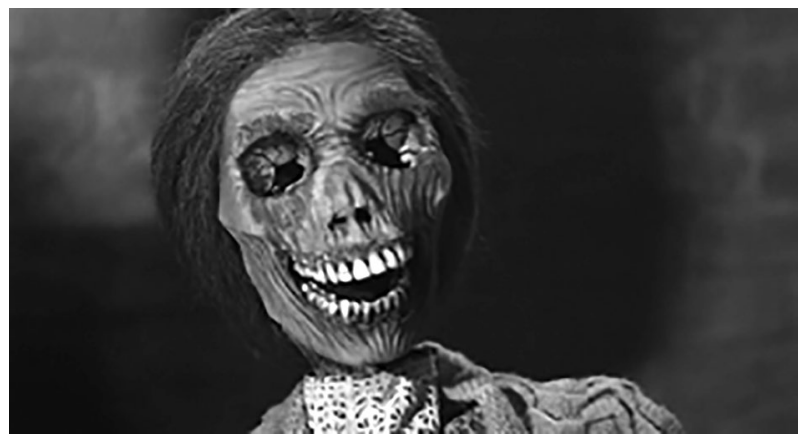

Imagen 14.

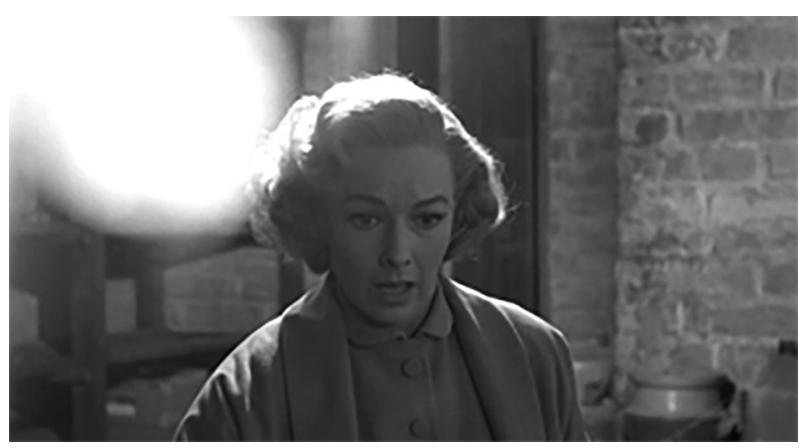

Imagen 15.

deben confrontarse. Lila logra ver sin perder la vida el rostro-mueca de la madre cruel. El grito, su rostro desencajado y la mirada fuera de campo apuntan hacia la naturaleza siniestra del contraplano. El plano/contraplano marca la distancia y, a la vez, refuerza la analogía como si se tratara de un dispositivo especular. Es decir, a pesar de su gesto de horror, Lila, y con ella el espectador, se reconoce de una manera violenta en esa máscara femenina, de la madre cruel [imágenes 14 y 15].

El balanceo de la lámpara propone un conflicto luz-sombra que oscila en el rostro de las mujeres. Este encuentro con una sombra de ascendencia expresionista forma parte de la narrativa del drama (identitario) del héroe, y preside la puesta en escena de tiempos relevantes en el difícil, y a menudo masoquista, trayecto de la heroína hitchcockiana, la mujer investigadora. Está presente, por ejemplo, en el acceso a la habitación prohibida en Rebeca, el dominio de la Sra. Danvers, y reaparece junto a la puerta del malvado director del psiquiátrico que abre la Dra. Constance en Recuerda. 
El anudamiento producido entre el sentido de la vista y la muerte, en esta perspectiva mortal de la madre monstruosa recuerda a la Górgona. En La muerte en los ojos, Pierre Vernant ha mostrado la relación entre la medusa y la alteridad, a través de la que se definió la identidad en la Antigua Grecia. En su estudio sobre este monstruo femenino, Pilar Pedraza ha reconducido el sentido de esta figura desde el relato dominante, aquel que la convierte en antagonista del héroe Perseo, hacia el de Atenea, la diosa de las artes y del combate. De manera que este monstruo femenino sería la contrafigura, un doble de Atenea (178 y ss.). El héroe Perseo regalará su cabeza a Atenea ${ }^{9}$, pasando a formar parte de su escudo o égida.

Esta significación cultural arroja luz sobre el encuentro de Lila con la madre monstruosa. Aunque finalmente sea salvada por Sam -el remake postmoderno (Gus van Sant, 1998) presenta a una Lila más activa y violenta-, es Lila quien descubre, en el sótano, tras haber transitado por las habitaciones prohibidas, de la madre y el hijo, a las que conduce la escalera donde murió Arbogast, y la del sótano, la estancia del inconsciente, el secreto mejor guardado durante todo el film. Tras haber visto a la momia femenina, Lila, situada abajo, logra tener una perspectiva reveladora y, a juzgar por su gesto, no menos terrorífica. Desde esta perspectiva Crane logra ver la personalidad escindida de Norman que ha fantaseado la figura de su madre. Su trayecto laberíntico concluye en este infierno psicótico donde se encuentra con un vacío terrorífico asociado con la madre y, por extensión, con el significante mujer (madre). La chica de Phoenix descubre la puesta en escena de la siniestra fantasía sobre la que se ha construido el film, reenviándolo a la realidad.

Sin embargo, de esta revelación no deriva la estabilidad final a la que se dirige el relato clásico. La terrorífica fantasía femenina del monstruo persiste en forma de amenaza. La secuencia epílogo regresa, una vez más, a la (oscura) dimensión realista del relato. Junto al resto de los hombres, Lila se convierte en destinataria de la explicación del psiquiatra, una vez más sobre «la historia de Norman», que responde a sus preguntas sobre su hermana. A pesar del descubrimiento ateneico de Lila, el film concluye con el protagonismo de esa imagen fantaseada de la mujer y el monstruo Norman a través de su voz en off. Tras mirar a cámara, reconociendo el lugar del espectador, Norman se transforma en la imagen cadavérica de la madre que parece emerger, por efecto del encadenado, de la profundidad del lago donde recuperan el coche de una de sus víctimas femeninas [imagen 16]. Aunque encerrada, bajo tutela

9. En la escultura en bronce de Perseo realizada por Cellini (1545-54), la cabeza de Medusa que el héroe sostiene con su mano guarda un inquietante parecido con Perseo. 


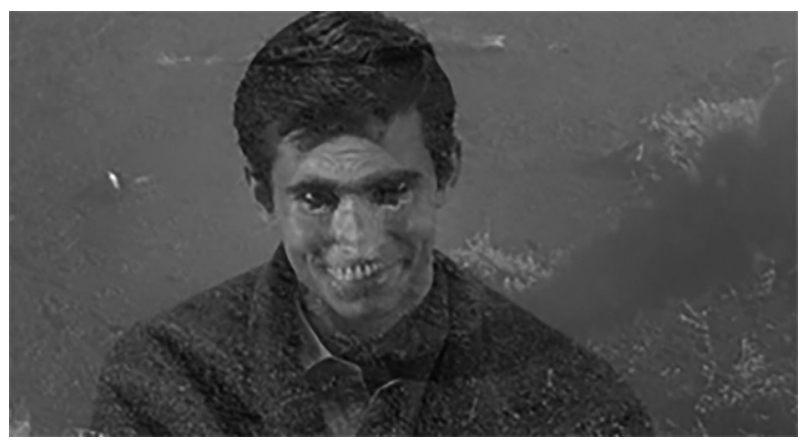

Imagen 16.

policial, la fantasía de la madre cruel sobre la que la mujer y el monstruo, los dos conceptos con los que se ha asociado desde una perspectiva masculina la alteridad en la cultura occidental, han proyectado oscuros e inquietantes deseos que amenazan el sistema social, desafía a la mirada del espectador.

\section{CONCLUSIONES}

En este film representativo de la quiebra de la narrativa clásica de Hollywood puede apreciarse un discurso metaficcional sobre la función asignada al punto de vista y la imagen narrativa de la mujer. La lectura dominante, centrada en «la historia de Norman», ha eclipsado que es la trayectoria de la feminidad la que cuestiona la estructura narrativa clásica, y deja paso a un desdoblamiento simbólico, significante cultural de la identidad, que expresa la resistencia de la mujer a definirse por el patrón manejado por el discurso institucional. La feminidad se representa como un viaje roto por el asesinato de Marion, pero que se desdobla en la otra hermana de Phoenix, que plantea la perspectiva privilegiada del relato.

El cuestionamiento de los arquetipos femeninos de la narrativa clásica se percibe, por una parte, en la deformación expresionista, en forma de fantasía, a la que se somete la figura de la madre-monstruo; y por otra, en la influencia de la estética noir. La estrecha relación estética del film con el estilo noir permite entender su discurso sobre la subjetividad femenina como un precedente del neonoir feminizante.

En el trayecto desdoblado de la perspectiva Crane se observa una transición entre dos arquetipos característicos de la modernidad. El primero, representado por Marion, se identifica con el rol noir de la mujer fatal que realiza un viaje identitario fuera de la ley, es decir, en contra del rol social asignado a la mujer. Este trayecto subversivo, progresivamente dominado por una fantasía 
expresionista, pondrá en contacto a la mujer con una visión fantasmal de la madre y con un hombre fatal. La moderna heroína del film se identifica, sin embargo, con la mujer investigadora con la que logramos tener el punto de vista Crane. Esta mujer investigadora retoma el papel del hombre investigador de la ficción negra para reconocer la fantasía masculina y femenina que recorre el film, el rostro cegado de la madre cruel.

En este moderno y neonoir arquetipo femenino puede reconocerse la influencia de la mujer gótica o paranoica que se ha definido como la versión femenina del noir. La diferencia principal es que el secreto a descubrir por Lila en la casa gótica no se relaciona con su marido, sino con la condición de ser madre. Aquí, la pareja formada por Sam y Lila forma parte de una puesta en escena. El personaje de Lila, además de relacionarse con la chica final (Clover) se convierte en un antecedente directo de la mujer investigadora del neonoir feminizante que empieza a producirse con más intensidad a partir de la década de los noventa.

Esta significación se ha extendido a films de la postmodernidad que revisan la representación de la mujer en en el film noir y que, no por casualidad, parodian Psicosis. Así, en El silencio de los corderos, la heroína encontrará un ave disecada en su trayecto, y su apellido, Starling, es el nombre de un pequeño pájaro, un estornino. La protagonista de Fargo (Coen, 1996), la policía Marge Gunderson aparece por primera vez, en el minuto 31 del film, tras el asesinato de una mujer, una mujer víctima, y un prolongado fundido a negro que marca una pausa en el relato: un travelling lateral que conduce la mirada del espectador mostrando las imágenes de unos patos hasta llegar a la cama donde duerme una embarazada mujer investigadora junto a su marido.

Su parodia postmoderna está lejos de ser un síntoma del escepticismo planteado en el arte contemporáneo hacia viejas fórmulas del pasado. Estas citas reflexivas constituyen una forma de homenaje a un incipiente y maltrecho discurso, no institucional, sobre «la historia de la mujer». En el cine de la postmodernidad, esta forma de representación se recicla y actualiza para proyectarla hacia el futuro.

\section{REFERENCIAS BIBLIOGRÁFICAS}

Allen, Richard. Hitchcock's Romantic Irony. Nueva York: Columbia University Press, 2007.

Antón, Laura. «La expresión de-l (lo) Otro en el relato audiovisual. Una aproximación a la figura narrativa del doble». Área Abierta 13.2 (2013): 1-21.

Antón, Laura. «El drama pasional de la mujer investigadora. Un arquetipo femenino de la crisis». Fotocinema 8 (2014): 57-82. 
Bellour, Raymond. L'analyse du film. Paris: Calmann-Lévy, 1995.

Bloch, Robert. Psicosis. Barcelona: La factoría de ideas, 2010.

Bolaños, Alejandro. «Portugal, Italia y España amplían la brecha salarial en la crisis». El País, 5 marzo 2015: sin p. <http://economia.elpais.com/economia/2015/03/05/actualidad >, consultado el 6-03-2015.

Castro de Paz, José Luis. Alfred Hitchcock. Madrid: Cátedra, 2000.

Clover, Carol J. Men, Women and Chain Saws in the Modern Horror Film. New Jersey: Princeton University Press, 1992.

Cortés, José Miguel G. Orden y caos. Un estudio cultural sobre lo monstruoso en el arte. Barcelona: Anagrama, 1997.

Creed, Barbara. «A Journey Through Blue Velvet: Film, Fantasy and the Female Spectator». New Formations 6 (winter 1988): 97-117.

Creed, Barbara. The Monstruous Feminine: Film, Feminism, Psychoanalysis. London: Routledge, 1993.

Doane, Mary Ann. The desire to desire. The woman's film of 1940's. London: The MacMillan Press, 1987.

Douchet, Jean. Hitchcock. París: L’Herne, 1985.

Freud, Sigmund. Obras completas. Madrid: Biblioteca Nueva, 1996.

Gil Calvo, Enrique. La mujer cuarteada. Utero, Deseo y Safo. Barcelona: Anagrama, 1991.

González Requena, Jesús. Clásico, manierista y postclásico. Valladolid: Castilla Ediciones, 2006.

Hitchcock, Pat y Laurent Bouzereau. Alma Hitchcock. La mujer tras el hombre. Barcelona: Circe, 2009.

Kolker, Robert (ed.). Alfred Hitchcok's Psycho. Oxford: University Press, 2004.

Kuhn, Annette. Cine de mujeres. Feminismo y cine. Madrid: Cátedra, 1991.

Modleski, Tania. Hitchcock et la théorie féministe. Les femmes qui en savaient trop. París: L'Harmattan, 2002.

Mulvey, Laura. Placer visual y cine narrativo. Valencia: Eutopías, 1985.

Offen, Karen. Feminismos europeos, 1700-1950. Una historia política. Madrid: Akal, 2000.

Paglia, Camille. Los pájaros. Barcelona: Gedisa, 1998.

Pedraza, Pilar. La bella, enigma y pesadilla. Barcelona: Tusquets, 1991.

Rebello, Stephen. Alfred Hitchcock and the Making of Psycho. EE.UU: Soft Skull Press, 2012.

Russo, Eduardo A. (ed.). Interrogaciones sobre Hitchcock. Buenos Aires: Simurg, 2001.

Spoto, Donald. Alfred Hitchcock. La cara oculta del genio. Madrid: T\&B Editores, 2004.

Spoto, D. Las damas de Hitchcock. Barcelona: Lumen, 2008.

Talens, Jenaro. El ojo tachado. Madrid: Cátedra, 2010. 
Trías, Eugenio. Lo bello y lo siniestro. Barcelona: Ariel, 2001.

Truffaut, François. El cine según Hitchcock. Madrid: Alianza Editorial, 1994.

Vernant, Jean Pierre. La muerte en los ojos. Barcelona: Gedisa, 1985.

Williams, Linda. «When the woman looks». Revision. Essays in Feminist Film Criticism. Eds. Mary Ann Doane, Patricia Mellencamp y Linda Williams. Los Angeles: The American Film Institute, University Publications of America, 1984, 61-66.

Žižek, Slavoj. Tout ce que vous avez toujours voulu savoir sur Lacan sans jamais oser le demander à Hitchcock. Francia: Navarin, 1988.

Žižek, Slavoj. Todo lo que usted siempre quiso saber sobre Lacan y nunca se atrevió a preguntarle a Hitchcock. Argentina: Manantial, 2001. 